\title{
Factors Affecting Adoption of Maize Cultivation Practices in Rajouri District of Jammu and Kashmir, India
}

\author{
Narinder Panotra ${ }^{1 *}$, Vinod Gupta ${ }^{2}$, Rohit Sharma ${ }^{3}$ and Ashwani Kumar ${ }^{4}$ \\ ${ }^{1}$ OFRC, SKUAST-Jammu, Jammu and Kashmir, India \\ ${ }^{2}$ KVK, Samba, SKUAST-Jammu, Jammu and Kashmir, India \\ ${ }^{3}$ RARS, Rajouri, SKUAST-Jammu, Jammu and Kashmir, India \\ ${ }^{4}$ Department of Agriculture, SKUAST-Jammu, Jammu and Kashmir, India \\ *Corresponding author
}

\section{A B S T R A C T}

\section{Keywords}

Maize, cultivation practices, adoption, Rajouri district

Article Info

Accepted:

20 August 2019

Available Online:

10 September 2019
The present study was undertaken in year 2014 and 2015 to study the factors affecting adoption of Maize cultivation practices in Rajouri district of Jammu and Kashmir. There were 160 Gram panchayats, 385 villages and 4 towns viz. Rajouri, Thanamandi, Nowshera and Sunderbani. The district constitutes 8.81 percent of the geographical area of the state. There are 7 revenue tehsils viz; Rajouri, Thanamandi, Nowshera, Sunderbani, Budhal and Darhal with a total of 9 revenue blocks in district Rajouri. Although agriculture is the main occupation of district Rajouri, but the farming community is perceived to be still following traditional agricultural practices. Therefore, the present study was conducted to examine the knowledge, attitude and extent of adoption of improved package of practices for Maize cultivation and to identify socioeconomic and personal factors which can affect the adoption of recommended practices of Maize. The study revealed that the majority of the respondents have low level of adoption and have medium level of attitude towards the cultivation practices of Maize.

\section{Introduction}

Maize (Zea mays L) is one of the most versatile emerging crops having wider adaptability under varied agro-climatic conditions. Globally, maize is known as queen of cereals because it has the highest genetic yield potential among the cereals. It is cultivated on nearly $150 \mathrm{~m}$ ha in about 160 countries having wider diversity of soil, climate, biodiversity and management practices that contributes $36 \%(782 \mathrm{~m} \mathrm{t})$ in the global grain production. Maize in India is known as 'King of cereals' because of its high 
production potential and wider adaptability. The increasing demand for maize and its global advance implies that by 2023 , maize will account for the greatest share $(34 \%)$ of the total crop area harvested (OECD-FAO, 2014). This poses particular challenges to the global capacity to sustainably supply the volumes of maize needed - particularly in low- and middle-income countries.

Indeed, rising demand has often expanded the maize area in these countries and brought new land into cultivation instead of sustainable intensification and increasing yields. Crop area thereby often expands into more marginal lands with potential threats to crop diversity, forests, and erodible hill slopes (Neumann et al., 2010).

In India, maize is the third important food crop after rice and wheat. According to latest data, it is being cultivated on $8.6 \mathrm{~m}$ ha with $80 \%$ area during Kharif season. The current maize production is $21.7 \mathrm{mt}$, with an average productivity of $2.5 \mathrm{t} / \mathrm{ha}$.

Despite maize being predominantly rainfed crop its productivity is more than rice which is mainly grown under assured irrigated/rainfed conditions. Maize contributes nearly $9 \%$ in the national food basket and more than 400 billion to the agricultural GDP at current prices. In addition it generates employment to over 1000 million man days at the farm and downstream agricultural and industrial sectors. Maize is primarily used for feed (60 \%) followed by human food $(24 \%)$, industrial (starch) products (14\%) beverages and seed (1\% each).

Maize is the most important and well-adopted cereal crop of Jammu and Kashmir and total areas sown 315.81 M. ha of maize in Jammu and Kashmir (Anon.2015). Being a major crop of the Jammu and Kashmir, it is grown in almost $80 \%$ as rainfed agriculture and forms the major crop in any crop rotation in the state.
Maize is the predominant crop in Rajouri district with an area of 46.8 thousand hectare and production and productivity of 136102.4 tonnes and $31.36 \mathrm{~kg} / \mathrm{ha}$ respectively. The Rajouri district of Jammu \& Kashmir state is situated between $32^{0} 98^{\prime}$ and $35^{\circ} 52^{\prime}$ ' North latitude and $74^{\circ} 01$ ' to $74^{0} 23^{\prime}$ 'East longitude.

The district touches Poonch, Pulwama, POK in the west and Jammu in the south. There are 160 Gram panchayats, 385 villages and 4 towns viz. Rajouri, Thanamandi, Nowshera and Sunderbani. The district constitutes 8.81 percent of the geographical area of the state. There are 7 revenue tehsils viz; Rajouri, Thanamandi, Nowshera, Sunderbani, Budhal and Darhal with a total of 9 revenue blocks. Keeping in view the above facts the present survey was undertaken to study the factors affecting adoption of Maize cultivation practices in Rajouri district.

\section{Materials and Methods}

The agro-climatic zones of Rajouri district ranges from high altitude temperate to subtropical type. Thus, cultivation of crops is possible round the year. The climate of the district varies according to altitude, the temperature rises sometimes as high as $38^{\circ} \mathrm{C}$ and seldom goes below $1.5^{\circ} \mathrm{C}$. Rajouri district lies between $32^{0} 58^{\prime}$ to $33^{0} 35^{\prime}$ North latitude and $74^{\circ}$ to $74^{\circ} 40^{\prime}$ East longitude surrounded by $120 \mathrm{~km}$ of Actual Line of Control with Pakistan.

The area of Rajouri district according to village records is about 253340 hectares. The gross irrigated area is 7385 hectares which is only $8 \%$ of the total cultivable area. This shows that farming community is mostly dependent on rains for the cultivation of $92 \%$ cultivable area. It is estimated that $90 \%$ population is residing in the rural areas and is mostly dependent on agriculture sector. The Rajouri district was purposively selected to be the area under investigation, because it was 
true representative district of Jammu and Kashmir on the basis of technological facilities available for Maize cultivation. Random samplings procedure were used for selection of research area and for selection of village clustered random sampling procedure were used.

Farm families were taken to be the unit of the study and the heads of the family as the respondents. 20 farmers from 5 villages were finally selected as respondents for the study. Accordingly from the five sample villages only 100 respondents finally selected for investigation. The data was collected with the help of interview schedule which was specially prepared for the study incorporating number of standard tools developed by different extension scientist in India, of course making necessary modifications of minor nature which were considered to be essential. In addition number of items of the interview schedule was developed by the author with the help of guide.

The purpose of the study was clearly explained to the respondents at the time of data collection. The data so collected were coded, classified, tabulated and analysed in the light of the objectives.

\section{Results and Discussion}

The present study are summarised below under relevant heads.

\section{Personal Attributes by Maize growers}

According to present study majority of respondents i.e. 34 per cent 'middle age' group. Most of them were educated to 'medium level'.

Technical Knowledge about improved Maize Production Technology by Maize growers

The level of Knowledge about the improved farm practices of the Respondents were 'Medium level' i.e 58 percent. 27 per cent respondents had 'Low Level' of knowledge and only 15 per cent respondents had 'high level' knowledge about the improved farm practices.

Extent of adoption of components of improved Maize Production Technology by Maize growers

Majority of respondents were widely adopted to Local variety of maize i.e. 36 per cent and percentage of recommended varieties C-8, Kanchan, KH-517, Pro Agro 4794, PG Hybrid, Double deklab were 15 per cent, 19 per cent, 6 per cent, 4 per cent, 8 per cent and 12 per cent respectively.

The adoption index shows that the high majority of respondents i.e., 48 per cent adopted to Maize cultivation at 'Low level' and 39 per cent were adopted to it at 'Medium Level' at least only 13 per cent of respondents grow to 'High Level'.

\section{Attitude towards improved Maize Production technology by Maize growers}

Majority of the respondents belongs to 'medium level' of attitudes i.e., 74 per cent, 18 per cent of farmer's having 'low level' of attitudes and only 8 per cent of respondents having 'High attitudes' towards improved Maize production technology.

\section{Extension Contact}

Majority of respondents belong to 'medium group' of extension contact i.e. 50 per cent. 27 per cent respondents had 'high' contact group and only 23 per cent respondents had 'low' extension contact towards improved Maize production technology. 
Table .1 Farmers distribution of Maize growers on socio-economic status

\begin{tabular}{|c|l|c|c|}
\hline Categories & Levels & Respondents & Percentages \\
\hline $\mathbf{1 3 - 2 0}$ & Very low & 7 & 7 \\
\hline $\mathbf{2 0 - 2 7}$ & Low & 24 & 24 \\
\hline $\mathbf{2 7 - 3 4}$ & Medium & 30 & 30 \\
\hline $\mathbf{3 4 - 4 1}$ & High & 34 & 34 \\
\hline $\mathbf{4 1 - 4 8}$ & Very High & 5 & 5 \\
\hline & Total & 100 & 100 \\
\hline
\end{tabular}

Table.2 Farmers knowledge of respondents about improved farm practices of Maize in Rajouri

\begin{tabular}{|c|l|c|c|}
\hline Categories & \multicolumn{1}{|c|}{ Level } & Number & Percentage \\
\hline $\mathbf{5 - 1 0}$ & Low & 27 & 27 \\
\hline $\mathbf{1 0 - 1 5}$ & Medium & 58 & 58 \\
\hline $\mathbf{1 5 - 2 0}$ & High & 15 & 15 \\
\hline & Total & 100 & 100 \\
\hline
\end{tabular}

Table.3 Farmers extent of adoption of Maize varieties.

\begin{tabular}{|c|l|c|c|}
\hline S.No. & Name of variety & Number & Percentage \\
\hline \hline $\mathbf{1 .}$ & Local & 36 & 36 \\
\hline $\mathbf{2 .}$ & C-8 & 15 & 15 \\
\hline $\mathbf{3 .}$ & Kanchan-612 & 19 & 19 \\
\hline $\mathbf{4 .}$ & KH-517 & 6 & 6 \\
\hline $\mathbf{5 .}$ & Pro Agro 4794 & 4 & 4 \\
\hline $\mathbf{6 .}$ & PG Hybrid & 8 & 8 \\
\hline $\mathbf{7 .}$ & Double Deklab & 12 & 12 \\
\hline & Total & 100 & 100 \\
\hline & & & \\
\hline
\end{tabular}

Table.4 Farmers Adoption Index of the Maize.

\begin{tabular}{|c|l|c|c|}
\hline Categories & \multicolumn{1}{|c|}{ Level } & Number & Percentage \\
\hline $\mathbf{1 - 8}$ & Low & 48 & 48 \\
\hline $\mathbf{8 - 1 6}$ & Medium & 39 & 39 \\
\hline $\mathbf{1 6 - 2 4}$ & High & 13 & 13 \\
\hline & Total & 100 & 100 \\
\hline
\end{tabular}


Table.5 Farmers Attitudes of Respondents

\begin{tabular}{|c|c|l|c|c|}
\hline S.No. & Categories & \multicolumn{1}{|c|}{ Level } & No. of Respondents & Percentage \\
\hline 1. & $34-38$ & Low & 21 & 21 \\
\hline 2. & $38-42$ & Medium & 69 & 69 \\
\hline 3. & $42-46$ & High & 10 & 10 \\
\hline
\end{tabular}

Table. 6 Distribution of respondents on the basis of Extension contact

\begin{tabular}{|c|c|l|c|c|}
\hline S.No. & Categories & Level & $\begin{array}{c}\text { No. of } \\
\text { Respondent }\end{array}$ & Percentage \\
\hline 1. & $0-5$ & Low contact group & 22 & 22 \\
\hline 2. & $5-10$ & Medium contact group & 48 & 48 \\
\hline 3. & $10-15$ & High contact group & 30 & 30 \\
\hline & & Total & 100 & 100 \\
\hline
\end{tabular}

Table .7 Distribution of respondents according to mass media Exposure

\begin{tabular}{|c|l|c|c|}
\hline Categories & \multicolumn{1}{|c|}{ Levels } & Respondent & Percentage \\
\hline $\mathbf{0 - 2}$ & Low & 30 & 30 \\
\hline $\mathbf{2 - 4}$ & Medium & 42 & 42 \\
\hline $\mathbf{4 - 6}$ & High & 28 & 28 \\
\hline & Total & 100 & 100 \\
\hline
\end{tabular}

Table.8 Problem's faced by Maize growers

\begin{tabular}{|c|l|c|c|}
\hline S.No. & Problems of Respondents & Number & Percentage \\
\hline 1. & Lack of improved and Resistant varieties. & 89 & 89 \\
\hline 2. & Unavailability of government facilities. & 85 & 85 \\
\hline 3. & High cost of improved seeds. & 80 & 80 \\
\hline 4. & High cost of manure and fertilizers. & 78 & 78 \\
\hline 5. & High cost of insecticides and pesticides. & 78 & 78 \\
\hline 6. & High losses in Maize by animals. & 76 & 78 \\
\hline 7. & Inadequate credit facilities. & 74 & 76 \\
\hline 8. & Lack of knowledge about improved practices. & 73 & 74 \\
\hline 9. & Negative role of Extension workers. & 73 \\
\hline
\end{tabular}


Fig.1

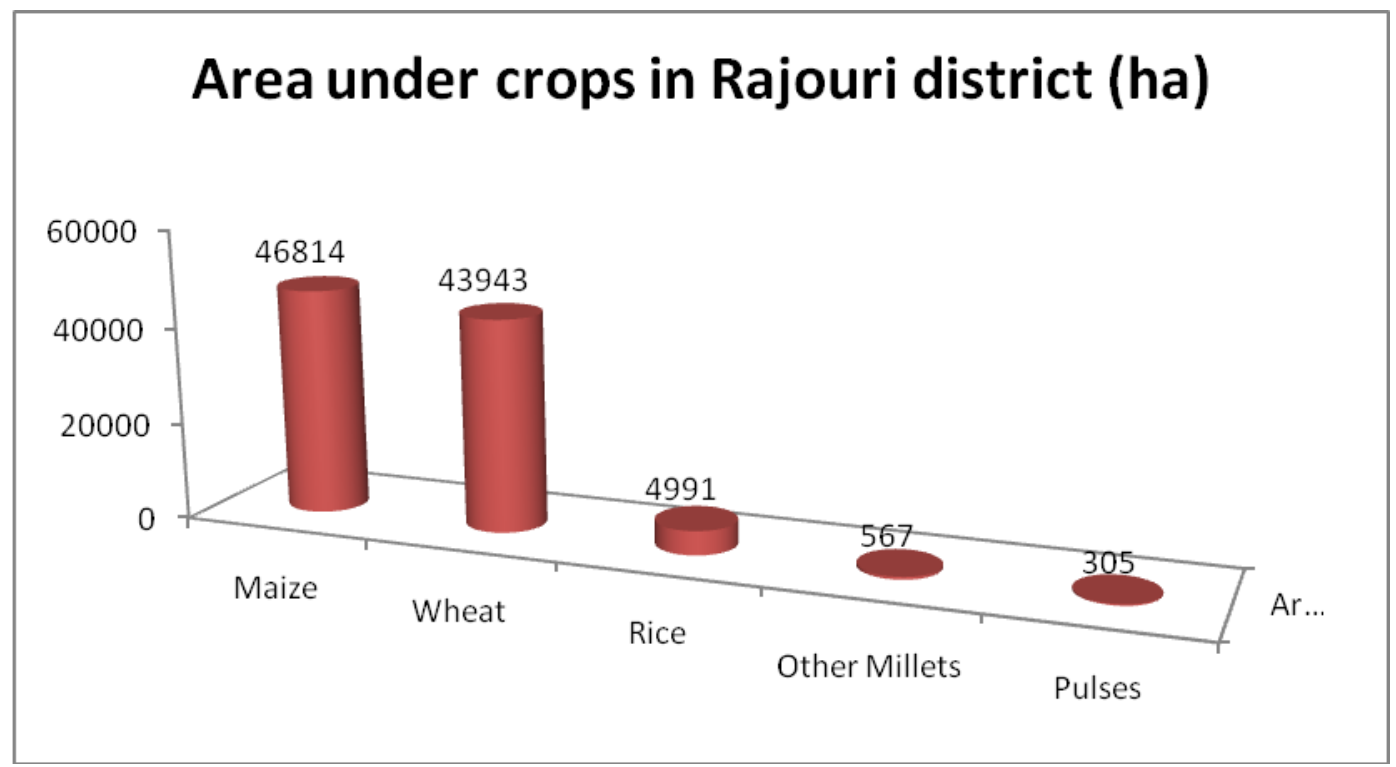

Mass Media Exposure by Maize growers

Majority of the respondents belongs to 'medium level' of mass media exposure i.e. 38 per cent. 37 per cent of farmer having 'low level' of mass media exposure and only 25 per cent respondents had 'high level' of mass media exposure.

It is clear from the study that respondents have knowledge about cultivation of Maize but their productions were not up to mark. The reason in order of importance for non-adopter of Package of practices of Black-Gram were lack of knowledge, lack of Encouragement by Extension Personnel, high cost of inputs and non availability of seeds of improved varieties and fertilizers in time.

\section{Problem faced by Maize growers}

Majority of respondents reported that the main problems of Maize growers were negative role of extension worker, lack of knowledge about improved Practices, inadequate credit facilities, high losses in Maize crop by animals, high cost of insecticide and pesticides, high cost of manure and fertilizers, high cost of improved seeds, problems of government facilities and lack of improved and resistant variety. Their percentage being 73 per cent, 74 per cent, 76 per cent, 78 per cent, 78 per cent, 79 per cent, 80 per cent, 85 per cent and 89 per cent respectively.

Majority of the farmers belong to 'middle age group' and most of them educated to 'medium level'. They have 'medium level' of knowledge about the improved farm practices of Maize. Majority of respondents were live in joint family and no member of any organizations. Most of the respondents belong to 'medium' caste and agriculture is the main occupation. Majority of respondents had 'medium level' of knowledge about improved farm practices of Maize. Most of respondents used the local variety of Maize. The adoption index shows that majority of respondents were not interested in cultivation of Maize. Majority of the respondents belongs to 'medium level' of attitudes towards improved Maize Production Technology. Majority of the respondents belongs to 'medium group' of extension contact towards improved Maize production technology. Majority of the respondents belongs to 'medium level' of 
mass media exposure. Majority of respondents also indicated that the main problems of Maize cultivation were lack of knowledge about improved practices, inadequate credit facilities, high losses in Maize crop by animals, high cost of insecticides and pesticides, high cost of manure and fertilizers, high cost of improved seeds, unavailability of government facilities and lack of improved and resistant varieties.

\section{References}

Agriculture statistics at a glance 2015. Ministry of Agriculture and Farmer's welfare. Government of India.

Anonymous 2016. Agricultural census, Directorate of economics and Statistics, Deptartment of Agriculture and Cooperation, Ministry of Agriculture, Government of India.

Anonymous 2015. Agricultural census, Directorate of economics and Statistics, Deptartment of Agriculture and Cooperation, Ministry of Agriculture, Government of India.

Ernest RS.1973. A study of communication utilization behaviour of small and big farmers and its implication to communication strategy, Ph.D. thesis (unpublished), IARI, New Delhi.

Jat MS 1972. A Study of consideration in decision making as related to the adoption H.Y.V. of wheat; a decade of Res. By Dr. R.P. Iingh, R.B.S. College Bichpuri, Agra U.P.

Kumar, P. and Satyanarayana, E. (2001). Variable and correlation studies of full season inbred lines of maize. J. Res., ANGARU 29: 71-75.

Manivannan, N. (1998), Character association and component analysis in maize. Madras Agric. J. 85: 293-294.

Netaji, S.V.S.R.K., Satyanarayana, E. and Suneetha, V. (2000). Heterosis studies for yield and yield component characters in maize (Zea mays L.). The Andhra Agric. J. 47: 39-42.

Sharma, R., Singh, P.P. and Sharma, R.N. (2000). Utility of farm information sources amongst tribals. Maha. J. Exten. Educ. XIX: 340-341.

Wakle, P.K., Wattamwar, V.T. nd Khalge, M.I. (1998). Utilization of different sources by maize growers for seeking farm information. Maha. J. Exten. Educ. XVII: 299-301.

\section{How to cite this article:}

Narinder Panotra, Vinod Gupta, Rohit Sharma and Ashwani Kumar 2019. Factors Affecting Adoption of Maize Cultivation Practices in Rajouri District of Jammu And Kashmir. Int.J.Curr.Microbiol.App.Sci. 8(09): 1980-1986. doi: https://doi.org/10.20546/ijcmas.2019.809.229 